\title{
Immune thrombocytopenia in a patient with COVID-19
}

\author{
Emilie Deruelle ${ }^{1} \cdot$ Omar Ben Hadj Salem ${ }^{1} \cdot$ Sonnthida Sep Hieng ${ }^{2} \cdot$ Claire Pichereau $^{1} \cdot$ Hervé Outin ${ }^{1}$. \\ Matthieu Jamme ${ }^{1,3}$ (B)
}

Received: 15 May 2020 / Revised: 3 July 2020 / Accepted: 7 July 2020 / Published online: 16 July 2020

(c) Japanese Society of Hematology 2020

\begin{abstract}
This case report describes immune thrombocytopenic purpura in a 41-year-old man hospitalized in the intensive-care unit for COVID-19, 13 days after the onset of COVID-19 symptoms with respiratory failure at admission. Acute respiratory distress syndrome was treated with, among other drugs, low-molecular-weight heparin. On day 8, his platelet count began descending rapidly. On day 10 , heparin treatment was replaced by danaparoid sodium, but by day 13 , the continued low platelet count made a diagnosis of heparin-induced thrombocytopenia unlikely. Normocytic nonregenerative anemia gradually developed. On day 13, a bone marrow aspiration showed numerous megakaryocytes and a few signs of hemophagocytosis. Corticosteroids were introduced on day 14, and platelets began rising after 3 days and then fell again on day 19. Intravenous immunoglobulin (IV Ig) was then administered. Two days later, the platelet count returned to normal. The immune cause was confirmed by ruling out the differential diagnoses and the excellent and rapid response to intravenous immunoglobulins. Finally, the patient's respiratory state improved. He was discharged to a respiratory rehabilitation unit on day 38 . Our case suggests that an immunological cause should be considered in patients with thrombocytopenia during COVID-19.
\end{abstract}

\section{Introduction}

Thrombocytopenia has recently been described as a frequent feature during the pandemic caused by the severe acute respiratory syndrome coronavirus 2 (SARS-CoV-2), which causes COVID-19, identified in up to $36 \%$ of patients [1]. The severity of thrombocytopenia has since been linked to the severity of COVID-19 and to its mortality [2-5].

Several physiopathological processes leading to thrombocytopenia during COVID-19 disease have been proposed [6-8]. It has been postulated that hematopoiesis dysfunction and alterations of megakaryocytic differentiation and maturation could occur through infection of hematopoietic stem cells and megakaryocytes, alterations of medullar microenvironment mediated by inflammation, and decrease of TPO production by liver cells which are susceptible to

Matthieu Jamme

Matthieu.Jamme@ght-yvelinesnord.fr

1 Intensive Care Unit, Poissy Saint Germain Hospital, 9-10 rue du champ Gaillard, 78300 Poissy, France

2 Laboratory of Hematology, Poissy Saint Germain Hospital, 9-10 rue du champ Gaillard, 78300 Poissy, France

3 INSERM U-1018, CESP, Team 5 (EpReC, Renal and Cardiovascular Epidemiology), UVSQ, Villejuif, France
SARS-CoV-2 infection. Lung injury mediated by SARSCoV-2 infection could also affect megakaryocyte fragmentation and platelet formation, which takes place in pulmonary vessels [9]. Moreover, pro-inflammatory mechanisms including cytokine and chemokine release have been documented in COVID-19, and could result in an increase of platelet consumption.

We report a case of immune thrombocytopenic purpura in a 41-year-old patient hospitalized in the intensive-care unit for COVID-19, with no history of immunologic disease.

\section{Case}

This 41-year-old man was admitted to the intensive-care unit at the Poissy-Saint Germain Intercommunal Hospital on March 28, 2020, for acute respiratory failure complicating COVID-19. He had a history of arterial hypertension and grade 1 obesity. He had complained of fever, cough, and dyspnea for the previous 13 days, and reported they had worsened on the day of admission.

On admission, his temperature was $38.7^{\circ} \mathrm{C}$. Clinical examination confirmed respiratory failure with a tachypneic respiratory rate of $40 / \mathrm{min}, \mathrm{SpO}_{2}$ of $97 \%$ under $15 \mathrm{~L} / \mathrm{min}$ of oxygen, and crackles at the bases of both lungs. The rest 
of the examination was normal. Hemodynamic parameters appeared normal.

Laboratory tests and chest imaging indicated mild acute respiratory distress syndrome (ARDS) according to the Berlin criteria [10], with the $\mathrm{PaO}_{2} / \mathrm{FiO}_{2}$ ratio at 213, bilateral opacities on chest radiography, and no evidence of cardiac failure. The total blood count showed no disorder, with leukocytes at $7950 / \mu \mathrm{L}$, hemoglobin of $13.8 \mathrm{~g} / \mathrm{dL}$,
Table 1 Laboratory data at ICU admission and during thrombocytopenia for etiological exploration

\begin{tabular}{|c|c|c|}
\hline & Patient value & Laboratory standards \\
\hline \multicolumn{3}{|l|}{ ICU admission } \\
\hline Leukocytes count (G/L) & 7.95 & $4-10$ \\
\hline Neutrophil & 5.69 & $1.5-7$ \\
\hline Lymphocytes & 1,85 & $1.3-4$ \\
\hline Monocytes & 0.4 & $0.1-1$ \\
\hline Eosinophil & 0 & $<0.7$ \\
\hline Basophil & 0.01 & $<0.2$ \\
\hline Hemoglobin $(\mathrm{g} / \mathrm{L})$ & 13.8 & $13-17$ \\
\hline MCV (fL) & $79^{\mathrm{a}}$ & $80-100$ \\
\hline Platelet count $(/ \mu \mathrm{L})$ & $261 \times 103 / \mu \mathrm{L}$ & $150.000-400.000$ \\
\hline Urea (mmol/L) & 3.4 & $3.2-7.4$ \\
\hline Creatinine $(\mathrm{mmol} / \mathrm{L})$ & 64 & $64-104$ \\
\hline ASAT (IU/L) & $115^{\mathrm{a}}$ & $5-34$ \\
\hline ALAT (IU/L) & $116^{\mathrm{a}}$ & $0-55$ \\
\hline GGT (IU/L) & $130^{\mathrm{a}}$ & $11-59$ \\
\hline Alkaline phosphatase (IU/L) & 55 & $40-150$ \\
\hline Total bilirubin $(\mu \mathrm{mol} / \mathrm{L})$ & 11 & $3-20$ \\
\hline $\mathrm{PT}(\%)$ & 85 & $70-120$ \\
\hline ATT & 1.12 & $<1.2$ \\
\hline $\mathrm{CRP}(\mathrm{mg} / \mathrm{L})$ & $63^{\mathrm{a}}$ & $<5$ \\
\hline Ferritin (ng/mL) & $3038^{\mathrm{a}}$ & $21-274$ \\
\hline LDH (IU/L) & $858^{\mathrm{a}}$ & $125-220$ \\
\hline D-Dimer (ng/ml) & $8435^{\mathrm{a}}$ & $<500$ \\
\hline \multicolumn{3}{|l|}{ Etiological exploration } \\
\hline Schizocytes search & Negative & $<1 \%$ \\
\hline Haptoglobin (g/L) & 3.41 & $0.14-2.58$ \\
\hline Ferritin (ng/mL) & 1906 & $21-274$ \\
\hline PT/ATT & $78 \% / 1.33$ & $70-120 /<1.2$ \\
\hline Fibrinogen $(\mathrm{g} / \mathrm{L})$ & 9.13 & $2-4$ \\
\hline Anti-PF4 antibody search & Negative & - \\
\hline HIV serology & Negative & - \\
\hline HBV serology & $\begin{array}{l}\text { HBs Ag negative, HBs Ab positive, } \\
\text { HBc Ab positive: cured infection } \\
\text { profile }\end{array}$ & - \\
\hline HCV serology & Negative & - \\
\hline EBV PCR & Detectable, unquantifiable & - \\
\hline CMV PCR & Negative & - \\
\hline Protein immunoelectrophoresis & Normal profile & - \\
\hline Antinuclear factor search & Negative & - \\
\hline Anti-cardiolipin antibody search & Negative & \\
\hline Anti-glycoprotein IIb/IIIa antibody search & Negative & \\
\hline Rheumatoid factor search & Negative & \\
\hline B lymphocyte immunophenotyping & Normal & - \\
\hline
\end{tabular}

${ }^{\text {aPathological value }}$ 
and a platelet count of $261 \times 10^{3} / \mu \mathrm{L}$. Prothrombin time and activated thromboplastin time were normal. Blood tests also showed symptoms of systemic inflammation, with increased CRP (63 mg/L), ferritin (3038 ng/mL), fibrinogen (769 mg/ dL), and mild liver cytolysis. D-Dimers were highly elevated $(8435 \mu \mathrm{g} / \mathrm{mL})$. Renal function was normal. Baseline characteristics are summarized in Table 1.

The nasopharyngeal SARS-CoV-2 RT-PCR results were positive.

ARDS was treated by protective mechanical ventilation, neuromuscular blocking agents, and preventive low-molecular-weight heparin (LMWH). Because bronchoalveolar lavage was positive for oropharyngeal flora, cefotaxime was administered as antibiotic treatment for 5 days.

On day 8 , the platelet count fell sharply, down to $24 \times 10^{3} /$ $\mu \mathrm{L}$ blood on day 10 , with mild bleeding in endotracheal tube secretions. The patient had received no drug except heparin that would normally be considered potentially responsible for thrombocytopenia, in particular, no quinine, inhibitors of proton pump or cimetidine, diuretics, or antistaphylococcal antibiotics (linezolid, vancomycin, or rifampicin). Because heparin-induced thrombocytopenia was suspected, LMWH was stopped and replaced with danaparoid sodium. No thrombotic events were recorded, and no anti-PF4 antibodies were found in a blood sample. The continued low platelet count for 5 days after the discontinuation of heparin therapy made the diagnosis of heparin-induced thrombocytopenia unlikely. Normocytic nonregenerative anemia gradually developed, with hemoglobin dropping to $7.8 \mathrm{~g} / \mathrm{dL}$, and endotracheal bleeding persisted. On day 13 , bone marrow aspiration showed numerous megakaryocytes (Fig. 1), and a few signs of hemophagocytosis. Table 2 summarizes the results of the bone marrow aspiration.

Apart from the persistent fever due to COVID-19 and a high triglyceride level presumably linked to the high-dose propofol required for sedation, there were no reliable signs of macrophage activation syndrome: serum ferritin continued to decrease to $1906 \mathrm{ng} / \mathrm{mL}$, liver function was normal, and there was no leukopenia.

Serologic tests were negative for HIV and HCV and positive for cured HBV. PCR results for CMV and parvovirus B19 PCR were negative, while results for EBV were moderately positive but not quantifiable. Testing for antinuclear factors was negative. Based on the results of the bone marrow examination, peripheral thrombocytopenia of immunological origin was deemed the most likely diagnosis. Etiological explorations are summarized in Table 1. No cytological or phenotypical indication of an underlying B lymphoproliferative syndrome was observed.

Platelets continued to fall, reaching $19 \times 10^{3} / \mu \mathrm{L}$ blood on day 14 , and a mild hemorrhagic syndrome persisted.

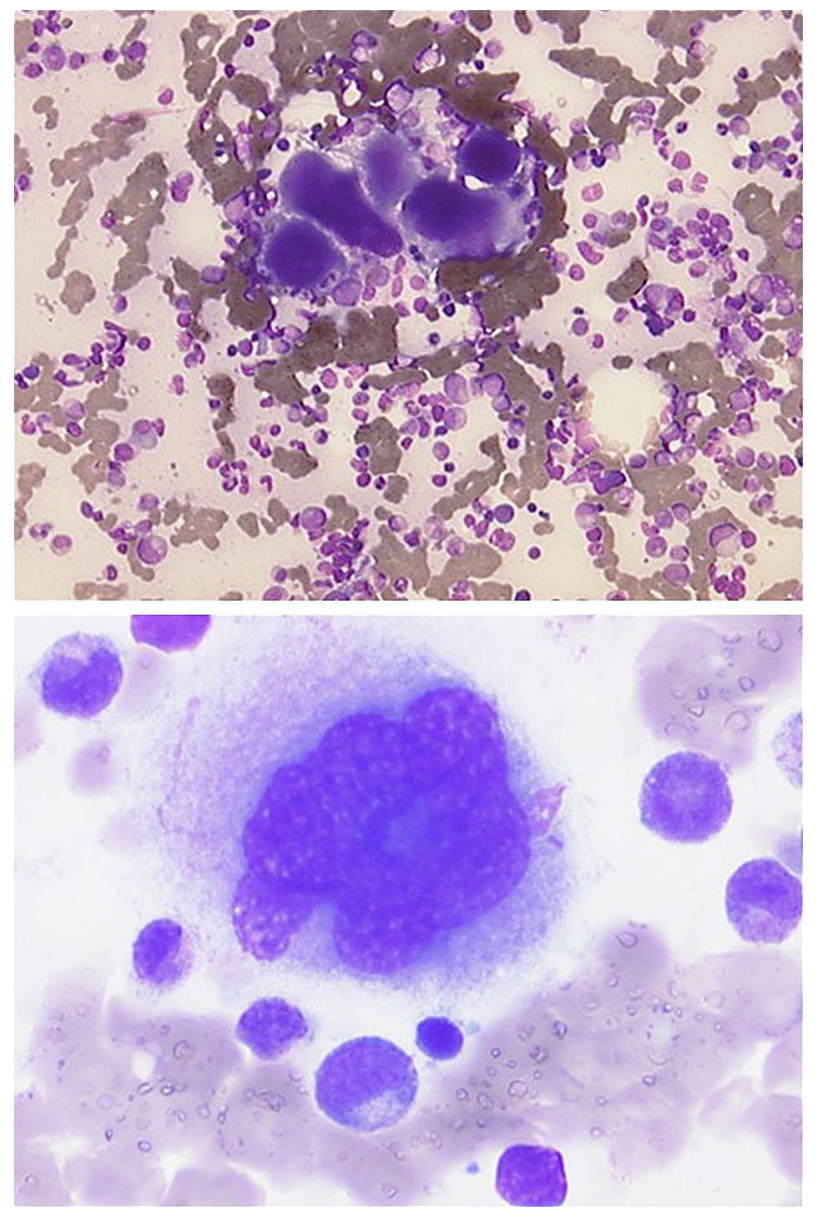

Fig. 1 Bone marrow aspiration showing rich medulla with numerous megakaryocytes $(\times 10$ in upper panel and $\times 50$ in the lower panel)

Accordingly, corticosteroids (IV methylprednisolone, $1 \mathrm{mg}$ / $\mathrm{kg} / \mathrm{day}$ ) [11] were introduced on day 14. After 3 days, the platelet count began rising, reaching $110 \times 10^{3} / \mu \mathrm{L}$ on day 18 . On day 19 , it fell again to $56 \times 10^{3} / \mu \mathrm{L}$ blood, with persistent bleeding. Intravenous immunoglobulin (IV Ig) was then administered ( $1 \mathrm{~g} / \mathrm{kg}$ on day 20) [11]. Two days later, the platelet count returned to normal. D-Dimers were measured at $2445 \mathrm{ng} / \mathrm{ml}$ on day 22 and were normal on day 29. Finally, the patient's respiratory state improved, enabling him to be weaned from sedation on day 30 and from mechanical ventilation on day 33 . He was discharged to a respiratory rehabilitation unit on day 38. Figure 2 illustrates the course of his platelet count and oxygenation over time. 
Table 2 Bone marrow aspiration analyses

\begin{tabular}{llc}
\hline & Results & $\begin{array}{c}\text { Laboratory } \\
\text { standard (\%) }\end{array}$ \\
\hline Hemoblasts & $0 \%$ & $0.5-2$ \\
Granulocytic lineage & $77 \%$ & $0.5-2$ \\
Myeloblasts & $5 \%$ & $1-5$ \\
Promyelocytes & $7 \%$ & $5-15$ \\
Neutrophilic, myelocytes & $23 \%$ & $15-20$ \\
Neutrophilic, metamyelocytes & $21 \%$ & $25-35$ \\
Neutrophilic, segmented & $21 \%$ & \\
Eosinophilic, segmented & $1 \%$ & \\
Monocytes & $3 \%$ & $0.5-2$ \\
Erythroid lineage & $13 \%$ & $2-5$ \\
Proerythroblasts & $1 \%$ & $6-12$ \\
Basophilic erythroblasts & $2 \%$ & $6-10$ \\
Polychromatic erythroblasts & $2 \%$ & $5-15$ \\
Acidophilic erythroblasts & $8 \%$ & $0.5-2$ \\
Lymphocytes & $2 \%$ & \\
Plasma cells & $4 \%$ & \\
Megakaryocytes & Numerous megakaryocytes & \\
Conclusion & Rich bone marrow. Granulous hyperplasia and numerous & \\
& megakaryocytes. Rare signs of hemophagocytosis & \\
\hline & & \\
& &
\end{tabular}

\section{Discussion}

The diagnostic approach to thrombocytopenia proved difficult in this case, due to the multiple potential causal factors.

Heparin-induced thrombocytopenia was first considered, but immunological investigations were negative, and thrombocytopenia persisted for several days after the heparin therapy was discontinued.

Macrophage activation syndrome was another plausible differential hypothesis, supported by several clinical and laboratory indications. Nonetheless, some of them were misleading: the fever and elevated ferritin levels could be linked to the coronavirus infection and to the inflammatory state, as could the sparse sign of hemophagocytosis in the bone marrow aspirate; and the triglyceride level could be related to the high dose of propofol. The decisive marker against this diagnosis was ferritin, which remained at a relatively low level and fell as the platelet count continued to deteriorate.

The bone marrow aspirate suggested a peripheral cause and called for a trial of corticosteroid treatment, as the thrombocytopenia was worsening rapidly. The
Fig. 2 Time-course evolution of platelet count and oxygenation

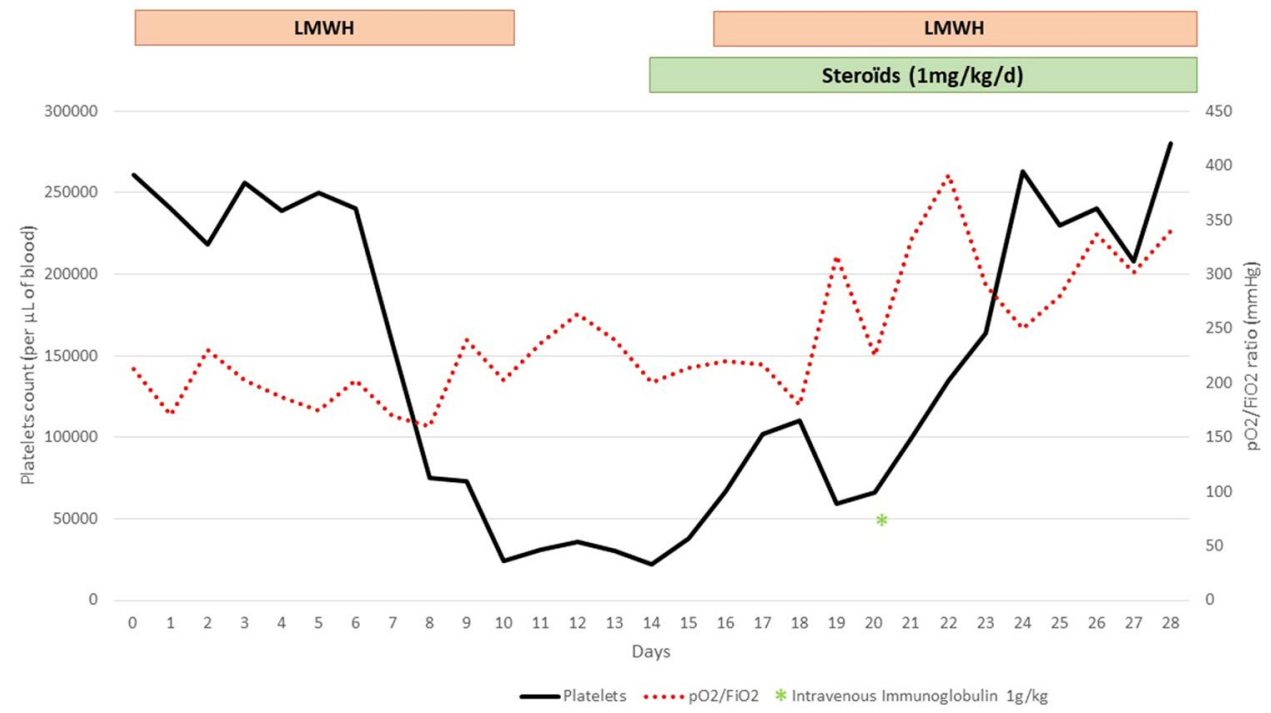


quick response to corticosteroid therapy, as well as to IV Ig strongly suggest that the hypothesis of immunological thrombocytopenia is correct.

Since it first appeared in late 2019, COVID-19's swift spread has confronted clinicians with difficult challenges in understanding its pathophysiological processes and in identifying predictive biomarkers.

Thrombocytopenia has been identified as a frequent feature [1-5], reported in 18-36\% of patients in different cohorts. It has also been associated with severe disease [2, 5] and mortality [3-5]. It was also a frequent feature of the SARS-CoV infectious epidemic of 2003 when it was reported in $40-50 \%$ of the patients [12, 13].

Various mechanisms might cause thrombocytopenia in SARS-CoV and SARS-CoV-2 infections [6-8]. Thrombocytopenia might also result from immunological peripheral destruction of platelets, as demonstrated in viral infections including HIV and HCV [14]. Cases of immune thrombocytopenic purpura associated with SARS-CoV-2 infection have recently been reported, both recurrence of chronic immune thrombocytopenic purpura $[15,16]$ or newly diagnosed, both adult or pediatric [17-27]. Recommendations have recently been issued to help the management of immune thrombocytopenia during the COVID-19 pandemic [28]. Although more common causes of thrombocytopenia must be investigated first, these cases suggest that an immunological cause should be considered in patients with COVID-19.

Acknowledgements The authors sincerely thank Didier Patte and Ms. Jo Ann Cahn for his help in preparing the manuscript.

Author contributions $\mathrm{ED}$ and $\mathrm{MJ}$ conceived and wrote the manuscript. SSH provided material support. OBHS, CP, YL, MA, CB, SMA, LLDS, JH, and HO wrote the manuscript. All authors reviewed the manuscript before submission.

\section{Compliance with ethical standards}

Conflict of interest None of the authors has a relevant conflict of interest.

\section{References}

1. Guan W, Ni Z, Hu Y, Liang W, Ou C, He J, et al. Clinical characteristics of coronavirus disease 2019 in China. N Engl J Med. 2020;382:1708-20. https://doi.org/10.1056/NEJMoa2002032.

2. Lippi G, Plebani M, Henry BM. Thrombocytopenia is associated with severe coronavirus disease 2019 (COVID-19) infections: a meta-analysis. Clin Chim Acta. 2020;506:145-8. https://doi. org/10.1016/j.cca.2020.03.022.

3. Liu Y, Sun W, Guo Y, Chen L, Zhang L, Zhao S, et al. Association between platelet parameters and mortality in coronavirus disease 2019: retrospective cohort study. Platelets. 2020. https:// doi.org/10.1080/09537104.2020.1754383.
4. Yang X, Yang Q, Wang Y, Wu Y, Xu J, Yu Y, et al. Thrombocytopenia and its association with mortality in patients with COVID19. J Thromb Haemost. 2020. https://doi.org/10.1111/jth.14848.

5. Jiang S, Huang Q, Xie W, Lv C, Quan X. The association between severe COVID-19 and low platelet count: evidence from 31 observational studies involving 7613 participants. Br J Haematol. 2020. https://doi.org/10.1111/bjh.16817(bjh.16817).

6. Xu P, Zhou Q, Xu J. Mechanism of thrombocytopenia in COVID19 patients. Ann Hematol. 2020. https://doi.org/10.1007/s0027 7-020-04019-0.

7. Terpos E, Ntanasis-Stathopoulos I, Elalamy I, Kastritis E, Sergentanis TN, Politou M, et al. Hematological findings and complications of COVID-19. Am J Hematol. 2020. https://doi.org/10.1002/ ajh.25829.

8. Zhang Y, Zeng X, Jiao Y, Li Z, Liu Q, Ye J, et al. Mechanisms involved in the development of thrombocytopenia in patients with COVID-19. Thromb Res. 2020;193:110-5. https://doi. org/10.1016/j.thromres.2020.06.008.

9. Lefrançais E, Ortiz-Muñoz G, Caudrillier A, Mallavia B, Liu F, Sayah DM, et al. The lung is a site of platelet biogenesis and a reservoir for haematopoietic progenitors. Nature. 2017;544:105-9. https://doi.org/10.1038/nature21706.

10. ARDS Definition Task Force, Ranieri VM, Rubenfeld GD, Thompson BT, Ferguson ND, Caldwell E, et al. Acute respiratory distress syndrome: the Berlin Definition. JAMA. 2012;307(23):2526-33.

11. Neunert C, Terrell DR, Arnold DM, Buchanan G, Cines DB, Cooper N, et al. American Society of Hematology 2019 guidelines for immune thrombocytopenia. Blood Adv. 2019;3:3829-66. https ://doi.org/10.1182/bloodadvances.2019000966.

12. Yang M, Li CK, Li K, Hon KLE, Ng MHL, Chan PKS, et al. Hematological findings in SARS patients and possible mechanisms (review). Int J Mol Med. 2004;14:311-5.

13. Yang M, Ng MHL, Li CK. Thrombocytopenia in patients with severe acute respiratory syndrome (review). Hematol Amst Neth. 2005;10:101-5. https://doi.org/10.1080/10245330400026170.

14. Franchini M, Veneri D, Lippi G. Thrombocytopenia and infections. Expert Rev Hematol. 2017;10:99-106. https://doi. org/10.1080/17474086.2017.1271319.

15. Merli M, Ageno W, Sessa F, Salvini M, Caramazza D, Mora B, et al. Recurrence of immune thrombocytopenia at the time of SARS-CoV-2 infection. Ann Hematol. 2020. https://doi. org/10.1007/s00277-020-04130-2.

16. Hu Z, Chen W, Liang W, Xu C, Sun W, Yi Y. Severe exacerbation of immune thrombocytopenia and COVID-19: the favorable response to corticosteroid-based therapy-a case report. Ann Hematol. 2020. https://doi.org/10.1007/s00277-020-04070-x.

17. Zulfiqar A-A, Lorenzo-Villalba N, Hassler P, Andrès E. Immune thrombocytopenic purpura in a patient with Covid-19. N Engl J Med. 2020. https://doi.org/10.1056/NEJMc2010472.

18. Lorenzo-Villalba N, Zulfiqar A-A, Auburtin M, Schuhmacher MH, Meyer A, Maouche Y, et al. Thrombocytopenia in the course of COVID-19 infection. Eur J Case Rep Intern Med. 2020;7:001702. https://doi.org/10.12890/2020_001702.

19. Murt A, Eskazan AE, Yilmaz U, Ozkan T, Ar MC. COVID-19 presenting with immune thrombocytopenia: a case report and review of the literature. J Med Virol. 2020;2020:jmv.26138. https ://doi.org/10.1002/jmv.26138.

20. Sadr S, SeyedAlinaghi S, Ghiasvand F, Hassan Nezhad M, Javadian N, Hossienzade R, et al. Isolated severe thrombocytopenia in a patient with COVID-19: a case report. IDCases. 2020;21:e00820. https://doi.org/10.1016/j.idcr.2020.e00820.

21. Humbert S, Razanamahery J, Payet-Revest C, Bouiller K, Chirouze C. COVID-19 as a cause of immune thrombocytopenia. Médecine Mal Infect. 2020. https://doi.org/10.1016/j.medma 1.2020.05.003. 
22. Tang MW, Nur E, Biemond BJ. Immune thrombocytopenia due to COVID-19 during pregnancy. Am J Hematol. 2020;2020:ajh.25877. https://doi.org/10.1002/ajh.25877.

23. See Tsao H, Chason MH, Fearon MD. Immune thrombocytopenia (ITP) in a SARS-CoV-2 positive pediatric patient. Pediatrics. 2020;2020:e20201419. https://doi.org/10.1542/peds.2020-1419.

24. Li M, Nguyen CB, Yeung Z, Sanchez K, Rosen D, Bushan S. Evans syndrome in a patient with COVID-19. Br J Haematol. 2020;2020:bjh.16846. https://doi.org/10.1111/bjh.16846.

25. Ahmed MZ, Khakwani M, Venkatadasari I, Horgan C, Giles H, Jobanputra $\mathrm{S}$, et al. Thrombocytopenia as an initial manifestation of COVID-19; case series and literature review. Br J Haematol. 2020;189:1057-8. https://doi.org/10.1111/bjh.16769.

26. Bomhof G, Mutsaers PGNJ, Leebeek FWG, Boekhorst PAW, Hofland J, Croles FN, et al. COVID-19-associated immune thrombocytopenia. Br J Haematol. 2020;2020:16850. https://doi. org/10.1111/bjh.16850.
27. Patel PA, Chandrakasan S, Mickells GE, Yildirim I, Kao CM, Bennett CM. Severe pediatric COVID-19 presenting with respiratory failure and severe thrombocytopenia. Pediatrics. 2020;2020:e20201437. https://doi.org/10.1542/peds.2020-1437.

28. Pavord S, Thachil J, Hunt BJ, Murphy M, Lowe G, Laffan M, et al. Practical guidance for the management of adults with immune thrombocytopenia during the COVID-19 pandemic. Br J Haematol. 2020;189:1038-43. https://doi.org/10.1111/bjh.16775.

Publisher's Note Springer Nature remains neutral with regard to jurisdictional claims in published maps and institutional affiliations. 